\title{
Impaired D-myo-Inositol 1,4,5-Triphosphate Generation from Cord Blood Polymorphonuclear Leukocytes
}

\author{
PASQUALE SANTORO, VALTER AGOSTI, DOMENICO VIGGIANO, ANTONIO PALUMBO, \\ TIZIANA SARNO, AND FILIPPO CICCIMARRA
}

Department of Pediatrics, University Federico II, Naples, Italy

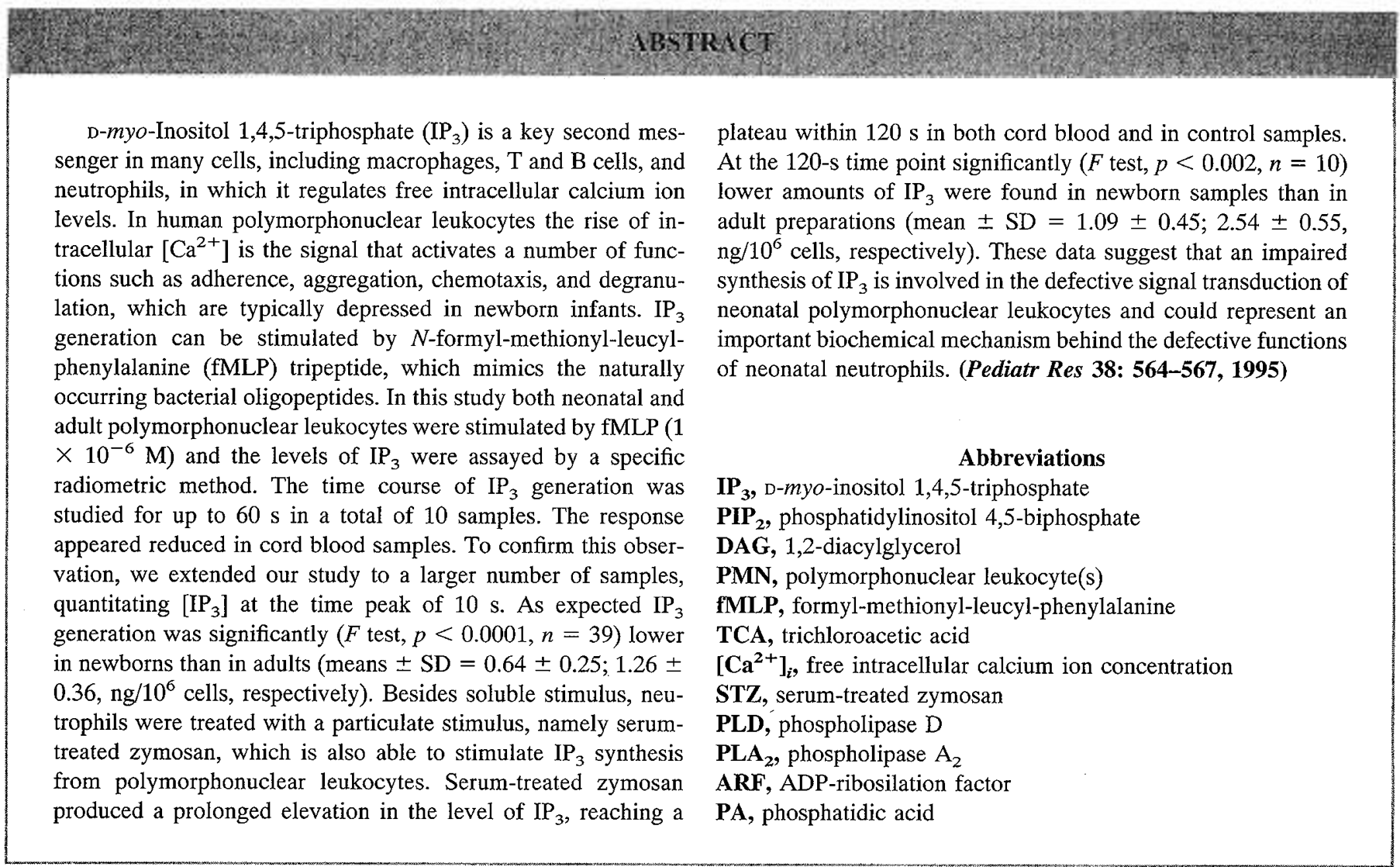

Human PMN are the first line of defense against nonviral infections. In response to an appropriate stimulus, they are able to diapedese through the endothelium and vessel wall in to the inflammatory focus killing and/or inactivating the invading organisms.

Newborn infants show an increased susceptibility to serious and overwhelming bacterial and fungal infections. This leads to increased morbidity and mortality, in spite of advances in antibiotic therapy. Although abnormalities have been described in all compartments of the neonatal host defense system (1),

Received July 14, 1994; accepted March 27, 1995.

Correspondence and reprint requests: Dr. Santoro Pasquale, Dipartimento di PediatriaCattedra di Neonatologia, Via Pansini, 5-80131 Naples, Italia. altered PMN functions are considered to be one of the main factors involved in susceptibility to infection (2).

FMLP is a synthetic tripeptide with structural and chemotactic characteristics similar to the naturally occurring bacterial oligopeptides (3). It is able to stimulate chemotaxis by binding to specific plasma membrane receptors of polymorphonuclear cells (4). The signal is transduced by the dissociation of the pertussis toxin-sensitive $\alpha$-GTP complex from the heterotrimeric $G$ protein and the consequent activation of a phospholipase $C(5,6)$. This, in turn, hydrolyzes PIP2 into two second messengers, namely DAG and $\mathrm{IP}_{3}$. The simultaneous generation of these two second messengers is responsible for activating a cascade of events that results in the cellular response. In particular, $\mathrm{IP}_{3}$ is able to mobilize $\mathrm{Ca}^{2+}$ from the intracellular 
stores through interaction with specific receptors $(5,7-9)$. The increase in free intracellular $\mathrm{Ca}^{2+}$ concentration is the signal activating many PMN functions such as diapedesis, chemotaxis, and phagocytosis $(10,11)$. These functions are typically depressed in newborns (12-14). In particular, both the chemotaxis response and the increase in $\left[\mathrm{Ca}^{2+}\right]_{\mathrm{i}}$ triggered by fMLP are deficient in newborns (15). In this study we assessed the production of $\mathrm{IP}_{3}$ in response to either fMLP or STZ, which is also able to stimulate the synthesis of $\mathrm{IP}_{3}$ from $\mathrm{PMN}$. The aim of this research is to investigate whether reduced synthesis of $\mathrm{IP}_{3}$ could play a role in impaired signal transduction in neonatal PMN.

\section{METHODS}

Sampling of blood. Heparin at a concentration of $20 \mathrm{U} / \mathrm{mL}$ was used as an anticoagulant. Venous blood was collected from the placenta vessels of full-term infants who were delivered vaginally. Newborns were the product of uncomplicated pregnancies and deliveries; neither general nor local anesthesia was administered to the mothers. No perinatal complications occurred in any of the babies studied, and they all had an Apgar score at 1 and $5 \mathrm{~min}>8$. Control cells were obtained from healthy adult donors.

The following steps of leukocytes separation started within $2 \mathrm{~h}$ of the blood collection.

Preparation of PMN suspensions. Neutrophils (95-97\% pure and $97-100 \%$ viable) were prepared and suspended in RPMI/FCS at a final concentration of $20-25 \times 10^{6}$ cells $/ \mathrm{mL}$ as previously described (16). All culture media were purchased as sterile and endotoxin-tested solutions from Sigma Chemical Co., St. Louis, MO.

fMLP stimulation. The synthetic tripeptide was purchased from Sigma Chemical Co. The PMN preparations were stimulated at $37^{\circ} \mathrm{C}$ at a final fMLP concentration of $1 \times 10^{-6} \mathrm{M}$.

To study the kinetic of $\mathrm{IP}_{3}$ production, $0.5 \mathrm{~mL}$ of fMLP was added to $2.5 \mathrm{~mL}$ of the cell suspension. Aliquots of $0.6 \mathrm{~mL}$ were pipetted from the incubation mixture and immediately mixed with an equal volume of ice-cold $15 \%$ TCA at the fixed time of $5,10,20,30$, and $60 \mathrm{~s}$. The samples were then kept on ice for $20 \mathrm{~min}$.

The stimulations at the peak value were performed by pipetting ice-cold TCA directly into the cell suspensions after exactly $10 \mathrm{~s}$.

STZ stimulation. Zymosan A was also from Sigma Chemical Co. STZ was prepared as previously described (16).

PMN preparations were stimulated at $37^{\circ} \mathrm{C}$ at a final concentration of $10 \mathrm{mg} / \mathrm{mL}$.

The kinetics of $\mathrm{IP}_{3}$ production were performed similarly to fMLP stimulation. The incubation was stopped at the fixed times of $10,60,120,150,180$, and $350 \mathrm{~s}$.

To reduce the variance within the groups in one way analysis of variance, we performed the stimulations at the time point of 120 s processing adult and cord blood samples simultaneously and in duplicate. We used the same pool of sera for the opsonization of zymosan A.
$I P_{3 \text { assay. }} \mathrm{IP}_{3}$ was extracted as previously described (16) and quantitated by a specific RIA (Amersham International plc, UK) (17).

Statistical analysis. The significance of differences between the groups was tested by one way analysis of variance.

\section{RESULTS}

$\mathrm{IP}_{3}$ generation in response to fMLP was assayed for up to 60 $\mathrm{s}$ in five samples of cord blood and five samples of adult PMN (Fig. 1A). fMLP produced a rapid increase in the level of $\mathrm{IP}_{3}$, which peaked at $10 \mathrm{~s}$ in all samples. The response appeared reduced in cord blood preparations. To confirm this observation, we extended our study to a larger number of samples (21 cord blood samples and 18 control adults), quantitating the $\mathrm{IP}_{3}$ generation at the time peak of $10 \mathrm{~s}$. Results are depicted in Figure $1 B$. Consistently, the response was significantly reduced in neonates compared with adults (means $\pm \mathrm{SD}=0.64 \pm$ $0.25 ; 1.26 \pm 0.36, \mathrm{ng} / 10^{6}$ cells, respectively, Fig. $1 B$ ). Oneway analysis of variance showed an $F$ value of $39.14, p<$ 0.0001 .

Although fMLP stimulation resulted in a transient increase in $\left[\mathrm{IP}_{3}\right], \mathrm{STZ}$ produced a prolonged increase in $\left[\mathrm{IP}_{3}\right]$, reaching a plateau within $120 \mathrm{~s}$ (Fig. $2 A$ ). These results agree with the findings of Burnham et al. (18). Similarly to fMLP, the response appeared lower in newborns than in adults. We performed additional experiments to confirm this finding, quantitating $\mathrm{IP}_{3}$ levels at $120 \mathrm{~s}$ in a total of 10 samples. As shown in Figure $2 B$, the response was significantly lower in cord than in adult $\mathrm{PMN}$ (mean $\pm \mathrm{SD}=1.09 \pm 0.45 ; 2.54 \pm 0.55, \mathrm{ng} / 10^{6}$ cells, respectively). One-way analysis of variance showed an $F$ value of $20.33, p<0.002$.

\section{DISCUSSION}

An increase in free intracellular $\mathrm{Ca}^{2+}$ concentration is an important signal activating several PMN functions, including diapedesis, chemotaxis, and phagocytosis $(10,11,19,20)$.

Although the mechanism involved in the regulation of $\left[\mathrm{Ca}^{2+}\right]_{\mathrm{i}}$ is far from clear, it is known that its release from
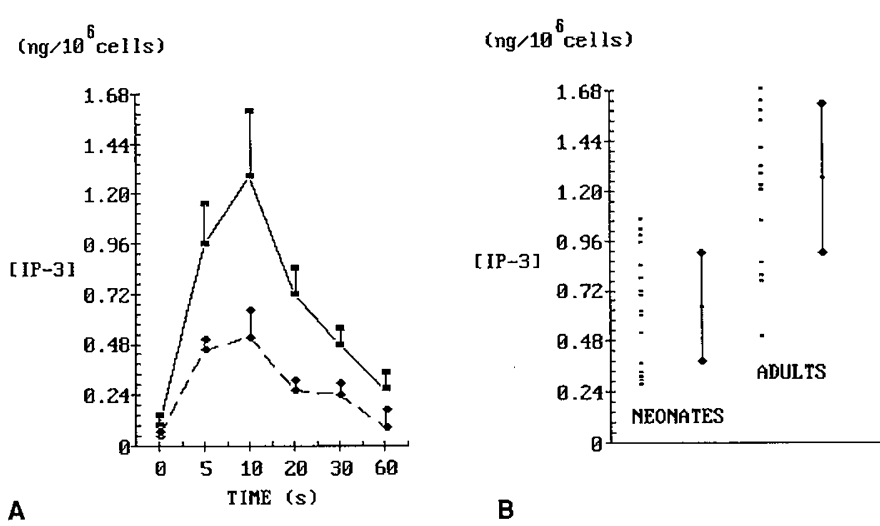

Figure 1. (A) Time course of fMLP-stimulated $\mathrm{IP}_{3}$ production by adult and cord blood PMN. (Solid line) $\mathrm{IP}_{3}$ production from adult neutrophils; (dashed line) $\mathrm{IP}_{3}$ production from neonate neutrophils. $(B)$ Peak $\mathrm{IP}_{3}$ production from cord blood and adult PMN in response to fMLP. Vertical bars represent the $\mathrm{SD}$. 


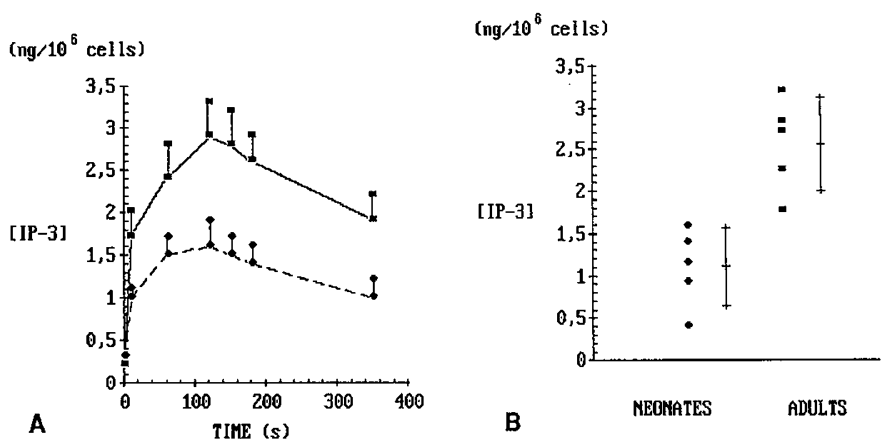

Figure 2. (A) Time course of STZ-stimulated $\mathrm{IP}_{3}$ production by adult and cord blood PMN. (Solid line) $\mathrm{IP}_{3}$ production from adult neutrophils; (dashed line) $\mathrm{IP}_{3}$ production from neonate neutrophils. Values are mean $\pm \mathrm{SD}$ of three experiments. $(B) \mathrm{IP}_{3}$ production at $120 \mathrm{~s}$ by neonatal and adult $\mathrm{PMN}$ in response to STZ. Vertical bars represent the SD.

intracellular stores may be directly stimulated by $\mathrm{IP}_{3}$ through the interaction with a specific intracellular receptor localized on the membrane of at least one specialized compartment of the endoplasmic reticulum $(5,7-9,20,21)$.

fMLP induces an impaired release of $\left[\mathrm{Ca}^{2+}\right]_{\mathrm{i}}$ in neonatal PMN (15), although previous studies reported a normal number of receptors for tritiated fMLP and that the affinity of the binding and dissociation is equivalent to that of PMN from adults $(22,23)$. We may conclude that a defect may occur in a specific step that follows the ligand-receptor interaction. Our results support the hypothesis that the low levels of $\left[\mathrm{Ca}^{2+}\right]_{i}$, generated by neonatal PMN in response to the chemotactic peptide, could be related to an impaired generation of $\mathrm{IP}_{3}$.

Along with fMLP, we studied the $\mathrm{IP}_{3}$ generation in response to a phagocytic stimulus. STZ is made up of zymosan particles, derived from yeast polysaccharide membranes, on which complement proteins and Ig are adsorbed. Interaction of opsonized zymosan with human PMN is prevalently mediated by receptors for C3 fragments (25).

The uptake of opsonized matter is an event that may occur independently of $\mathrm{IP}_{3}$ and $\left[\mathrm{Ca}^{2+}\right]_{\mathrm{i}}(24,26,27)$. However, during phagocytosis the uptake of particles is directly followed by other cellular events, such as the intracellular killing of microorganisms, the digestion of the ingested material, and the fusion of the granule membranes with the membrane of the phagosome. These events are related to $\mathrm{IP}_{3}$ levels and calcium metabolism: the fusion between different granules and the plasma membrane is $\mathrm{Ca}^{2+}$-dependent $(28,29)$; in $\mathrm{Ca}^{2+}$. depleted neutrophils the respiratory burst during phagocytosis of yeast-C3b/bi was found to be depressed by approximately $70 \%$ and the generation of inositol phosphate, DAG, PA, and arachidonate do not occur (27).

Reduced synthesis of $\mathrm{IP}_{3}$ in neonatal PMN may result in an impaired activation of the two $\left[\mathrm{Ca}^{2+}\right]_{i}$ dependent phospholipases: PLA ${ }_{2}$ and PLD. The latter is a downstream effector of ARF1 and ARF3 (30). ARF belong to the Ras superfamily that participates in the process of intracellular vesicular transport, in endocytosis and they may also function in endosomeendosome fusion $(30,31)$. The former directly cleaves arachidonic acid from membrane bound phospholipids and converts it, by the 5-lipoxygenase pathway into leukotrienes. We have previously reported that an impaired release of $\mathrm{LTB}_{4}$, which has an important role in initiating and amplifying the inflammatory response of human PMN, may be involved in the biochemical and functional abnormalities of PMN in the neonate (16).

The low levels of $\mathrm{IP}_{3}$ we found in neonatal PMN after fMLP or STZ stimulation could be due to either increased metabolism of the molecule or reduced synthesis and/or hydrolysis of $\mathrm{PIP}_{2}$. However, because of kinetic studies show that neonatal PMN metabolize $\mathrm{IP}_{3}$ similarly to that of the adult PMN, we hypothesize that the impaired signal transduction of neonatal PMN is due to a defect at a stage between the ligand-receptor interaction and $\mathrm{PIP}_{2}$ breakdown. If this is true, the consequence is a low generation of both the second messengers $\mathrm{IP}_{3}$ and $\mathrm{DAG}$, which are simultaneously generated by the $\mathrm{PIP}_{2}$ hydrolysis (9).

In conclusion our study supports the hypothesis that low levels of $\mathrm{IP}_{3}$ could play a role in the impaired response of neonatal PMN to an adequate stimulus and that there is the possibility that concomitant low levels of DAG may ulteriorly impair the capacity of activation of these cells.

\section{REFERENCES}

1. Wilson CB 1986 Immunological basis for increased susceptibility of the neonate to infection. J. Pediatr 108:1-12

2. Hill HR 1987 Biochemical, structural and functional abnormalities of polymorphonuclear leukocytes in the neonate. Pediatr Res 22:375-382a

3. Schiffmann E, Corcoran BA, Wohl SM $1975 \mathrm{~N}$-Formyl-methionyl peptides as chemoattractant for leukocytes. Proc Natl Acad Sci USA 72:1059-1064

4. Sklar LA, Jesaitis AJ, Painter RG 1984 The neutrophil $N$-formyl peptide receptor: dynamics of ligand-receptor interactions and their relationship to cellular responses. In: Snydernam R (ed) Regulation of Leukocyte Function. Plenum Press, New York, pp $29-82$

5. Melvin IS, Michael PS Narasimhan G 1991 Diversity of G proteins in signal transduction. Science 252:808

6. Cockroft S, Geraint MHT 1992 Inositol-lipid-specific phospholipase C isoenzymes and their differential regulation by receptors. Biochem J 288:1-14

7. Von Tscharner V, Prod'hom B, Baggiolini M 1986 Ion channels in human neutrophils activated by a rise in free cytosolic calcium concentration. Nature 324:369-372

8. Smrcka AV, Hepler JR, Brown OK, Stermweis PC 1991 Regulation of polyphosphoinositide-specific phospholipase $C$ activity by purified $G_{\mathrm{q}}$. Science $251: 804-807$

9. Berridge MJ 1987 Inositol triphosphate and diacylglycerol two interacting second messengers. Ann Rev Biochem 56:159-193

10. Bengtsson T, Stendahl O, Anderson T 1986 The role of the cytosolic free $\mathrm{Ca}^{2+}$ transient for fMet-Leu-Phe induced actin polymerization in human neutrophils. Eur $\mathrm{J}$ Cell Biol 42:338-343

11. Sklar LA, Omann GM, Painter RG 1985 Relationship of actin polymerization and depolymerization to light scattering in human neutrophils dependence of receptor occupancy and intracellular $\mathrm{Ca}^{2+}$. J Cell Biol 101:1161-1166

12. Krause PJ, Herson VC, Boutin-Lebowits J, Einsenfeld L, Block C, LoBlello T, Maderazo EG 1986 Polymorphonuclear leukocyte adherence and chemotaxis in stressed and healthy neonates. Pediatr Res 20:296-300

13. Anderson DC, Freeman KB, Heerdt B 1987 Abnormal stimulated adherence of neonatal granulocytes impaired induction of surface Mac-1 by chemotactic factors of secretagogues. Blood 70:74-45

14. Klein RB, Fischer TJ, Gard SE, Biberstein M, Rich KC, Stiehm ER 1977 Decreased mononuclear and polymorphonuclear chemotaxis in human newborns infants and young children. Pediatrics 60:467-472

15. Sacchi $\mathrm{f}$ Hill HR 1984 Defective membrane potential change in neutrophils from human neonates. J Exp Med 160:1247-1252

16. Viggiano D, Romano G, Caniglia M, Santoro P, Palumbo A, Ciccimarra F 1994 Impaired leukotriene $B_{4}$ release by neonatal polymorphonuclear leukocytes. Pediatr Res 36:60-63

17. Palmer S, Hughes KT, Lee DY, Wakelam MJO 1989 Development of a novel, Ins $(1,4,5) \mathrm{P}_{3}$-specific binding assay. Its use to determine the intracellular concentration of Ins $(1,4,5)_{3}$ in unstimulated and vasopressin stimulated rat hepatocytes. Cell Signalling 1:147-156

18. Burnham DN, Tyagi SR, Uhlinger DJ and Lambeth JD 1989 Diacylglycerol and phosphoinositide turnover in human neutrophils: effects of particulate versus soluble stimuli. Arch Biochem Biophys 269:345-353

19. Pinching AJ, Nye KE 1990 Defective signal transduction- a common pathway for cellular dysfunction in HIV infection? Immunol Today 11:256-259

20. Petersen Ole N., Wakui M 1990 Oscillating intracellular $\mathrm{Ca}^{2+}$ signal evoked by activation of receptors linked to inositol lipid hydrolysis: mechanism of generation. J Membr Biol 118:93-105 
21. De Young GW and Keizar J 1992 A single pool inositol 1,4,5-triphosphate-receptorbased model for agonist stimulated oscillation in $\mathrm{Ca}^{2+}$ concentration. Proc Natl Acad Sci USA 89:9895-9899

22. Anderson DC, Hughes BJ, Smith CW 1981 Abnormal mobility of neonatal polymorphonuclear leukocytes: relationship to impaired redistribution of surface adhesion sites by chemotactic factor or colchicine. J Clin Invest 68:863-874

23. Strauss RG, Snyder EL 1984 Chemotactic peptide binding by intact neutrophils from human neonate. Pediatr Res 18:63-66

24. Rosales C, Brown EJ 1992 Signal transduction by neutrophil immunoglobulin G Fc receptors-dissociation of intracytoplasmatic calcium concentration rise from inositol 1,4,5 triphosphate. J Immunol 267:5265-5271

25. Ezekowitz RAB, Sim RB, MacPherson GG, Gordon S 1985 Interaction of human monocytes, macrophages and polymorphonuclear leukocytes with zymosan in vitro. J Clin Invest 76:2368-2376

26. Lew DP, Andersson TA, Hed J, Di Virgilio F, Pozzan T, Stendhal O $1985 \mathrm{Ca}^{2+}$. dependent and $\mathrm{Ca}^{2+}$-independent phagocytosis in human neutrophils. Nature 315:509-511
27. Della Bianca V, Grzeskowiak M, Rossi F 1990 Studies on molecular regulation of phagocytosis and activation of the NADPH oxidase in neutrophils. J Immunol 144:1411-1417

28. Lew DP, Monod A, Waldvogel FA, Dewald B, Baggiolino M, Pozzan T 1976 Quantitative analysis of the cytosolic free calcium dependency of exocytosis from three subcellular compartments in intact neutrophils. J Cell Biol 102:21972204

29. Fallman, M Lew DP, Stendhal O, Andersson T 1989 Receptors-mediated phagocytosis in human neutrophils is associated with increased formation of inositol phosphates and diacylglycerol. J Clin Invest 84:886-891

30. Cockroft S, Geraint MHT, Fensome A, Geny B, Cunningham E, Gout I, Hiles I, Totty NF, Truong O, Hsuan JJ 1994 Phospholipase D: a downstream effector of ARF in granulocytes. Science 263:523-526

31. Lenhard JM, Kahn RA, Sthal PD 1992 Evidence for ADP-ribosilation factor (ARF) as a regulator of in vitro endosome-endosome fusion. $J$ Biol Chem 267:13047-13052 